\title{
Determination of pressure gradient in mitral stenosis with Doppler echocardiography
}

\author{
JARLE HOLEN AND SVEIN SIMONSEN \\ From the Department of Radiology, Department of Medicine B, and Institute for Surgical Research, \\ University Hospital, Rikshospitalet, Oslo, Norway
}

SUMMARY The accuracy of a non-invasive ultrasound Doppler technique for the determination of the pressure gradient in mitral stenosis was evaluated in a study of 8 adult patients. Transseptal left atrial catheterisation and retrograde left ventricular catheterisation were performed. The same diastoles were used to compare the gradient constructed from the ultrasound data $\left(\triangle \mathbf{P}_{\mathrm{U}}\right)$ with that constructed from the manometric data $\left(\triangle \mathbf{P}_{\mathbf{M}}\right)$. In the 8 patients the difference between the mean diastolic values of $\triangle \mathbf{P}_{U}$ and $\triangle P_{M}$ was $-0.54 \pm 1.0(S D) \mathrm{mmHg}$. The corresponding figure for mid-diastole was $0.01 \pm 0.9$ (SD) $\mathrm{mmHg}$. The results indicate that the ultrasound technique is sufficiently accurate for diagnostic purposes.

In an initial study of a non-invasive ultrasound Doppler technique for the determination of the pressure gradient in mitral stenosis (Holen et al., 1976) it was found that ultrasound can consistently register the frequency shifts from the diastolic mitral jet, and that the pressure gradient determined with ultrasound $\left(\triangle P_{U}\right)$ agrees reasonably well with the manometric gradient $\left(\triangle \mathbf{P}_{\mathbf{M}}\right)$ obtained from the pulmonary capillary venous and left ventricular pressures. Subsequent ultrasound studies of more than 150 patients with mitral stenosis have reinforced this impression.

Received for publication 30 November 1977
The present investigation was undertaken to explore the accuracy of the technique more closely by comparing $\triangle \mathbf{P}_{\mathrm{U}}$ with the manometric gradient obtained from left atrial (transseptal) and left ventricular pressures.

\section{Subjects and methods}

Data were collected from 8 adult patients undergoing routine preoperative cardiac catheterisation for mitral valve disease (Table).

ULTRASOUND SYSTEM

The frequency shifts from the mitral jet were

Table Data and numerical results on cases (gradients rounded off to nearest $\mathrm{mmHg}$ )

\begin{tabular}{|c|c|c|c|c|c|c|c|c|c|c|}
\hline \multirow[t]{2}{*}{ Case no. } & \multirow[t]{2}{*}{ Age } & \multirow[t]{2}{*}{$S \in x$} & \multirow[t]{2}{*}{$H R$} & \multirow[t]{2}{*}{$\boldsymbol{R}$} & \multirow[t]{2}{*}{$\dot{Q}$} & \multirow[t]{2}{*}{ Valve lesion } & \multicolumn{4}{|c|}{ Gradients ( $m m H g)$} \\
\hline & & & & & & & \multicolumn{2}{|c|}{ Mean diastolic } & \multicolumn{2}{|c|}{ Mid-diastolic } \\
\hline $\begin{array}{l}1 \\
2 \\
3 \\
4 \\
5 \\
6 \\
7 \\
8 \\
\bar{X} \\
\text { SD }\end{array}$ & $\begin{array}{l}66 \\
52 \\
54 \\
66 \\
46 \\
66 \\
30 \\
56 \\
55 \\
11\end{array}$ & $\begin{array}{l}\mathrm{F} \\
\mathrm{M} \\
\mathrm{M} \\
\mathrm{F} \\
\mathrm{F} \\
\mathrm{F} \\
\mathrm{M} \\
\mathrm{M}\end{array}$ & $\begin{array}{l}90 \\
68 \\
64 \\
58 \\
60 \\
76 \\
86 \\
70 \\
72 \\
12\end{array}$ & $\begin{array}{l}\text { AF } \\
\text { SR } \\
\text { SR } \\
\text { SR } \\
\text { AF } \\
\text { AF } \\
\text { AF } \\
\text { SR }\end{array}$ & $\begin{array}{l}3 \cdot 1 \\
4 \cdot 2 \\
4 \cdot 4 \\
8 \cdot 0 \\
3 \cdot 4 \\
7 \cdot 7 \\
8 \cdot 0 \\
5 \cdot 6 \\
2 \cdot 3\end{array}$ & $\begin{array}{l}\text { MS, MR } \\
\text { MS, MR, AR } \\
\text { MS } \\
\text { MS } \\
\text { MS } \\
\text { MS } \\
\text { MS } \\
\text { MS }\end{array}$ & $\begin{array}{r}14 \\
7 \\
11 \\
4 \\
13 \\
9 \\
13 \\
11 \\
10 \cdot 3 \\
3.5\end{array}$ & $\begin{array}{r}14 \\
8 \\
13 \\
5 \\
13 \\
8 \\
13 \\
12 \\
10.8 \\
3.3\end{array}$ & $\begin{array}{r}15 \\
8 \\
10 \\
3 \\
11 \\
9 \\
13 \\
9 \\
9 \cdot 8 \\
3 \cdot 7\end{array}$ & $\begin{array}{r}15 \\
8 \\
11 \\
5 \\
11 \\
9 \\
12 \\
9 \\
10.0 \\
3.0\end{array}$ \\
\hline
\end{tabular}

HR, heart rate; $\mathbf{R}$, rhythm; $\mathbf{Q}$, cardiac output $(1 / \mathrm{min}) ; \triangle \mathbf{P}_{U}$, gradient from ultrasound data; $\triangle \mathbf{P}_{M}$, gradient from manometric data; MS, mitral stenosis; MR, mitral regurgitation; AR, aortic regurgitation; SR, sinus rhythm; $A F$, atrial fibrillation; $\bar{X}$, mean value; and $\mathrm{SD}$, standard deviation. 
obtained with a modified (Holen et al., 1976) 2.1 $\mathrm{MHz}$ continuous waveform Hewlett-Packard 8026B Sound Monitor. The ultrasound data were recorded on magnetic tape and subsequently frequencyanalysed on a Kay Sona-Graph 6061B Sound Spectrum Analyzer. The hard copy of the frequency analysis is a grey scaled presentation wherein the abscissa is time and the ordinate frequency shift (Fig. 1b-4b). The degree of blackening at any particular point in the frequency analysis is in theory related to the energy present in the reflected sound, but electronic noise can also produce blackening. In the present investigation frequency analysis of the obtained Doppler spectrum was performed so that the time course of the maximum diastolic frequency shift $\left(\triangle \mathbf{f}_{\max }\right)$ could be identified. In the frequency analysis $\Delta f_{\max }$ is a curve drawn to envelop the blackening caused by the diastolic blood velocities. In order to identify $\Delta \mathbf{f}_{\max }$ as accurately as possible it is important that there is ample contrast between blackening from blood velocities and blackening from electronic noise. This contrast is in part dependent upon instrumentation, instrument settings, and ultrasound probe position.

\section{MANOMETRIC SYSTEM}

Left atrial and left ventricular pressures were obtained via $8 \mathrm{~F}$ catheters. The catheters were connected to EMT-34 transducers (Elema Schönander) and pressures recorded by a Mingograph system.

\section{COLLECTION OF DATA}

The ultrasound and manometric data were collected simultaneously with the patient resting in the supine position. Immediately before the collection of data the optimum probe position on the patient's left anterior or lateral chest wall was identified with the aid of the audio signal of the Doppler spectrum (the optimum probe position is defined as that in which the incident sound beam is in acoustic contact with the diastolic mitral jet with its axis as closely aligned with the direction of the vectors with maximum diastolic velocity as is possible). This was accomplished by identifying the probe position where the audio signal of the diastolic Doppler spectrum seemed to contain the largest amount of high frequency sound. With the probe in the optimum position the ultrasound and manometric data were recorded simultaneously, provision being made for the identification of individual cardiac cycles in both so that the results from individual diastoles could be compared.

\section{CONSTRUCTION OF GRADIENTS FROM}

ULTRASOUND AND MANOMETRIC DATA

The construction of the diastolic time course of the gradient from the ultrasound data was based upon three assumptions :

(1) The registered time course of $\Delta f_{\max }$ reflected the maximum blood velocities in the mitral orifice.

(2) The probe position during data collection was such that the axis of the incident sound beam coincided with the direction of the vectors with maximum velocity in the orifice, thus allowing $\cos \theta=1$ in the Doppler equation (Kinsler and Frey, 1962),

$\mathrm{V}_{\max }=\frac{\mathrm{c} \cdot \Delta \mathrm{f}_{\max }}{2 \cdot \mathrm{f} \cdot \cos \theta} \quad$ Doppler equation

Where, $V_{\max }=$ maximum blood velocity, $c=$ velocity of sound in blood, $\Delta \mathrm{f}_{\max }=$ maximum frequency shift, $f=$ frequency of incident sound beam, and $\theta=$ angle between axis of incident sound beam and direction of vectors with maximum blood velocity.

(3) The steady state orifice equation (eq. 2) (Streeter, $1961)$ is valid for the flow in stenotic mitral orifices

$\triangle P=\frac{1}{2} \rho\left(V_{\max }\right)^{2} \quad$ Orifice equation

where $\triangle P=$ pressure gradient, $\rho=$ mass density of blood, and $\mathrm{V}_{\max }=$ maximum blood velocity.

Thus, $\Delta P=\frac{1}{2} \rho\left[\frac{\mathrm{c} \cdot \Delta \mathrm{f}_{\max }}{2 \cdot \mathrm{f} \cdot \cos \theta}\right]^{2}$

And $\triangle P=\frac{1}{2} \rho\left[\frac{\mathrm{c}^{2}}{2^{2} \cdot \mathrm{f}^{2} \cdot \cos ^{2} \theta}\right] \cdot \Delta \mathrm{f}_{\max }{ }^{2}$

Using $\mathrm{c}=1.57 \cdot 10^{5} \mathrm{~cm} / \mathrm{s}$ (Hertz, 1977), $\mathrm{f}=2 \cdot 1$. $10^{6} \mathrm{~Hz}, \cos \theta=1$, and $\rho=1 \cdot 06 / 981 \mathrm{~g} \mathrm{~s}^{2}$ per $\mathrm{cm}^{4}$ (Diem and Lentner, 1962) and using 1.36 for $\mathrm{mmHg}$ conversion yields the following working equation $\triangle \mathbf{P}=$

$$
\frac{1}{1 \cdot 36} \cdot \frac{1}{2} \cdot \frac{1 \cdot 06}{981}\left[\frac{1 \cdot 57^{2} \cdot 10^{10}}{2^{2} \cdot 2 \cdot 1^{2} \cdot 10^{12}}\right] \cdot \triangle \mathrm{f}_{\max ^{2}} \cdot 10^{6}
$$

or $\triangle P_{U}=0.55 \cdot \Delta f_{\max ^{2}}$

where $\triangle \mathbf{P}_{\mathrm{U}}=$ pressure gradient determined from ultrasound data $(\mathrm{mmHg})$ and $\Delta \mathrm{f}_{\max }=$ maximum diastolic frequency shift $(\mathrm{kHz})$.

The time course of $\Delta f_{\max }$ was drawn by hand on the hard copy of the frequency analysis as a curve enveloping the blackened areas representing diastolic blood velocities. The time course of $\triangle \mathbf{P}_{\mathrm{U}}$ was then constructed from $\Delta \mathbf{f}_{\max }$ using eq. 3. The time course of the manometric gradient $\left(\triangle \mathbf{P}_{M}\right)$ was constructed from the values obtained by subtracting the left ventricular diastolic pressure from the left atrial diastolic pressure. 

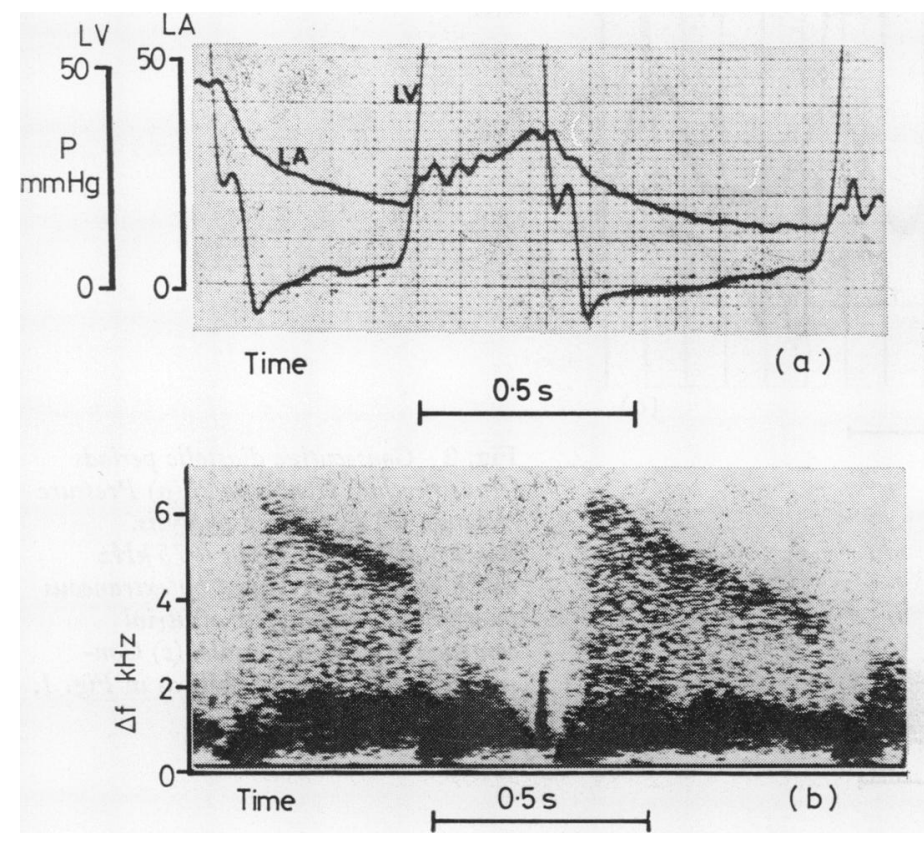

Fig. 1 Two consecutive diastolic periods (atrial fibrillation) from case 1. (a) Pressure tracings. $P$, pressure; $L V$, left ventricle; $L A$, left atrium.

(b) Frequency analysis. $\Delta f$, frequency shift. A hypothetical curve enveloping blackened diastolic areas will represent time course of maximum diastolic frequency shift. Note blackened band of about $0.5 \mathrm{kHz}$ width adjacent to

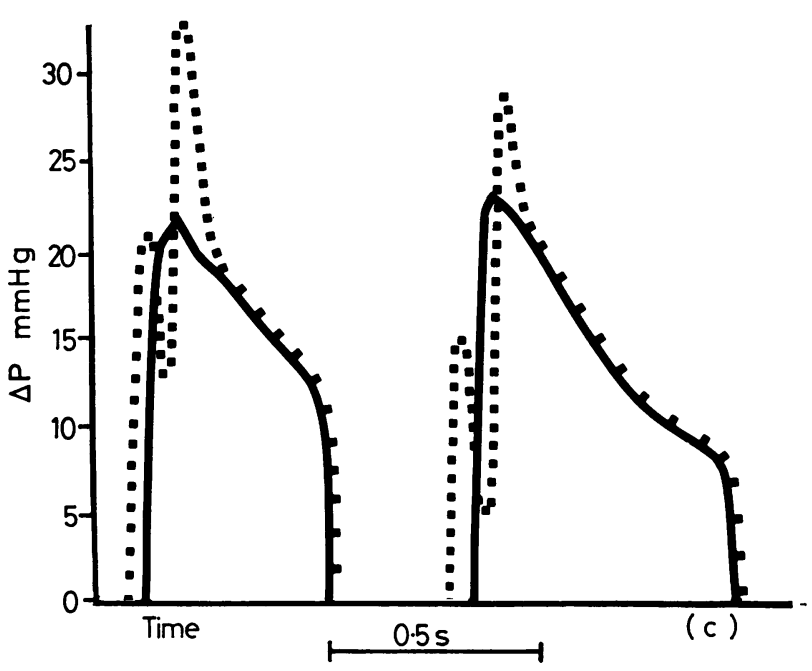
maximum frequency shift (most prominent in the first diastolic period). (c) Constructed gradients. $\triangle P$, pressure gradient; —, gradient from ultrasound data; - --, gradient from manometric data.

\section{COMPARISON OF $\triangle P_{U}$ AND $\triangle P_{M}$}

In general gradients were constructed from 3 to 4 consecutive diastolic periods in each patient. Comparisons were made of the mean diastolic and the mid-diastolic values of $\triangle \mathbf{P}_{\mathrm{U}}$ and $\Delta \mathbf{P}_{\mathbf{M}}$.

\section{Results}

Representative pressure recordings, frequency analyses, and constructed gradients are presented in Fig. 1 to 4 . In any given patient there was minimal variation in the quality of the recordings. A total of 28 diastolic periods were analysed and the gradients constructed.

The curve representing $\Delta f_{\max }$ was drawn by hand as a line demarcating the relatively heavy blackening caused by blood velocities from the lighter blackening produced by electronic noise. With the exception of the extremes of diastole the accuracy with which the location of $\triangle f_{\max }$ could be determined was estimated as $\pm 1 / 8$ (SD) $\mathrm{kHz}$. According to eq. 3 this corresponds to \pm 0.4 (SD), 

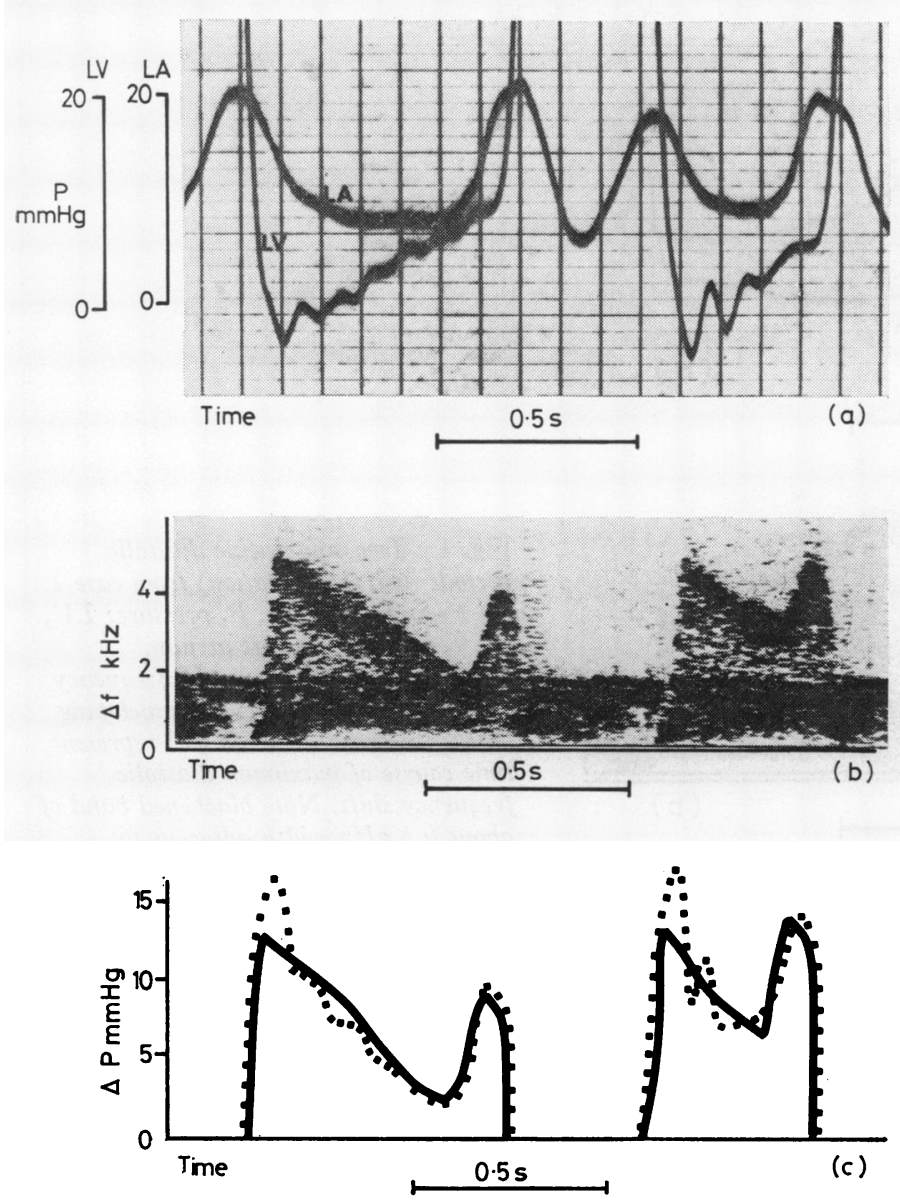

Fig. 2 Consecutive diastolic periods (sinus rhythm) from case 2. (a) Pressure tracings. (b) Frequency analysis. Blackened band of about $0.75 \mathrm{kHz}$ width at $2 \mathrm{kHz}$ is caused by extraneous interference. Note effect of atrial contraction in late diastole. (c) Constructed gradients. Symbols as in Fig. 1. \pm 0.6 (SD), \pm 0.7 (SD), and \pm 0.8 (SD) $\mathrm{mmHg}$ for gradients of $5,10,15$, and $20 \mathrm{mmHg}$, respectively. Near the extremes of diastole where $\Delta \mathbf{f}_{\max }$ was less than $2 \mathrm{kHz}$ the frequency shifts caused by the mitral jet were obscured in some patients by blackening from valve motion and ventricular blood velocities. In these regions $\Delta f_{\max }$ was drawn as a straight line continuation of the definable part of the curve.

The rate of change with time of $\Delta f_{\max }$ was greatest immediately after the onset of diastolic flow and immediately before its cessation. Relatively rapid changes in $\Delta f_{\max }$ also occurred during atrial contraction, whereas in general conditions approaching a steady state prevailed in mid-diastole (Fig. 1b to $4 b$ ).

With the exception of one patient (Fig. 4b), the frequency analyses exhibited a band of relatively heavy blackening adjacent to $\Delta \mathbf{f}_{\max }$ in the midportion of diastole.
The left ventricular pressure tracings showed early diastolic oscillation in all patients (Fig. 1a to 4a) and the effect of this oscillation was prominent in the constructed time course of $\triangle P_{M}$ (Fig. 1c to 4c). Similar oscillation was not observed in the frequency analyses or in left atrial pressure tracings. In patients in sinus rhythm the effect of atrial contraction was distinctly shown in both $\triangle P_{U}$ and $\triangle P_{M}$ (Fig. 2c to 4c). In early diastole and during atrial contraction, peak $\Delta \mathbf{P}_{M}$ invariably exceeded peak $\triangle \mathbf{P}_{\mathrm{U}}$. The major discrepancies between $\triangle \mathbf{P}_{\mathrm{U}}$ and $\triangle P_{M}$ were found in association with these gradient peaks.

In the 8 patients the mean diastolic value of $\Delta \mathbf{P}_{M}$ was 5 to $14 \mathrm{mmHg}$ (Table). The difference between the mean diastolic value of $\triangle \mathbf{P}_{\mathrm{U}}$ and the mean diastolic value of $\Delta P_{M}$ was $-0.54 \pm 1.0$ (SD) mmHg. The corresponding value for the middiastolic gradients was $0.01 \pm 0.9$ (SD) $\mathrm{mmHg}$. 

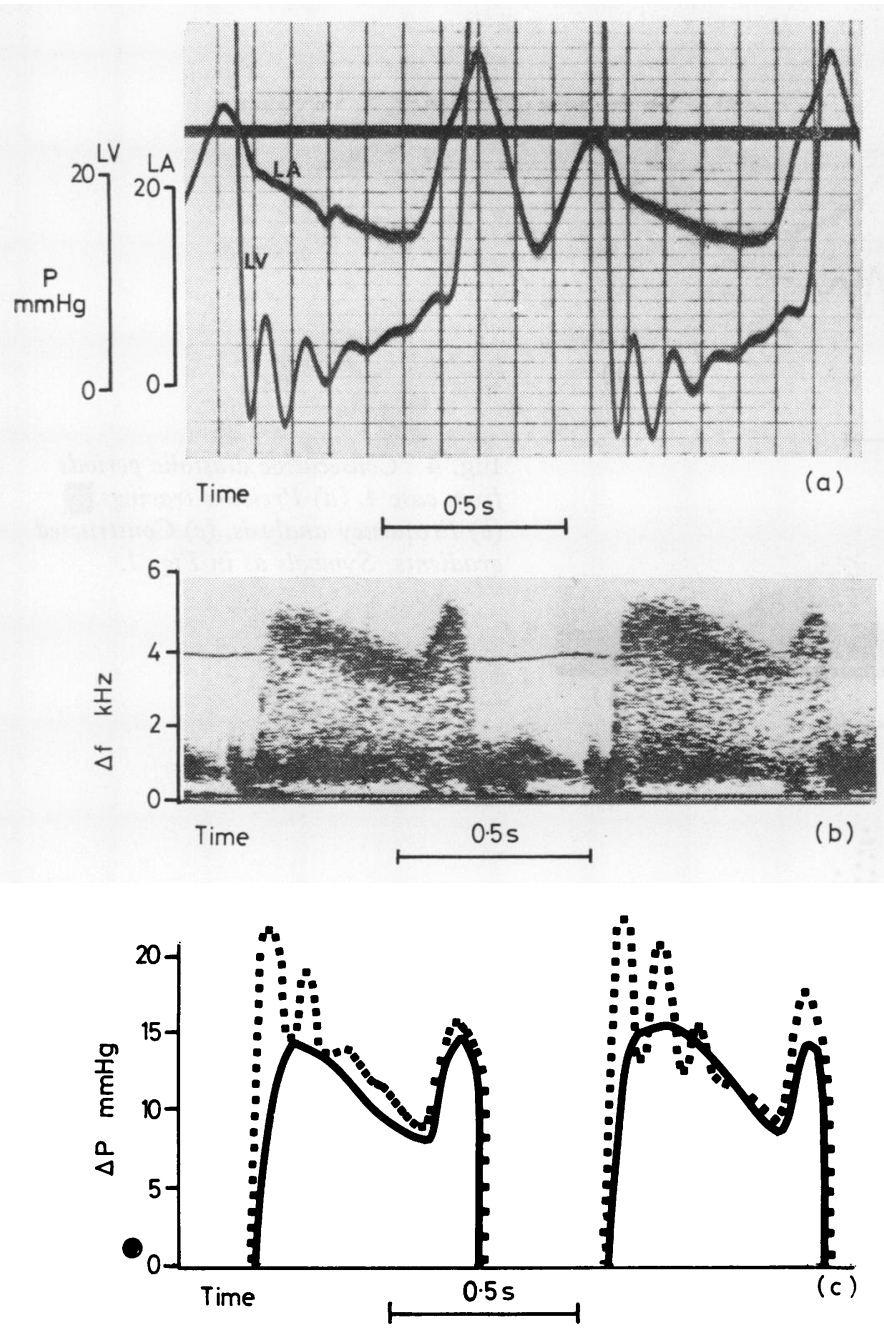

Fig. 3 Consecutive diastolic periods from case 3. (a) Pressure tracings. Note oscillation in tracing from left ventricle. (b) Frequency analysis. (c) Constructed gradients. Symbols as in Fig. 1 .

\section{Discussion}

The liquid-filled catheters used in the manometric system are likely to produce significant errors in $\triangle \mathrm{P}_{\mathrm{M}}$ in the vicinity of the rapid pressure changes. The oscillation in the left ventricular pressure tracings supports this contention. Peak values and timing of $\triangle \mathbf{P}_{M}$ therefore may well be erroneous.

The pressure gradient in mitral stenosis can be considered as the sum of an inertial and a dissipative (frictional loss) component. The steady state orifice equation (eq. 2) neglects the inertial component; thus $\Delta P_{U}$ will also misrepresent the actual gradient during rapid pressure changes and this can be expected to influence the value of the mean diastolic gradient more than the mid-diastolic one. The finding that agreement between mid-diastolic values of $\Delta \mathbf{P}_{\mathrm{U}}$ and $\Delta \mathbf{P}_{\mathrm{M}}$ was slightly better than that between mean diastolic values may reflect this; alternatively, it is possible that the difference in agreement is chiefly the result of errors in $\triangle \mathbf{P}_{\mathbf{M}}$. In any event it appears that neglect of the inertial component of the gradient has only a minimal influence on the agreement between the mean diastolic values of $\triangle P_{U}$ and $\triangle P_{M}$.

The orifice equation also neglects frictional losses incurred upstream of the flow sector where blood velocity is at its maximum. The mid-diastolic agree- 

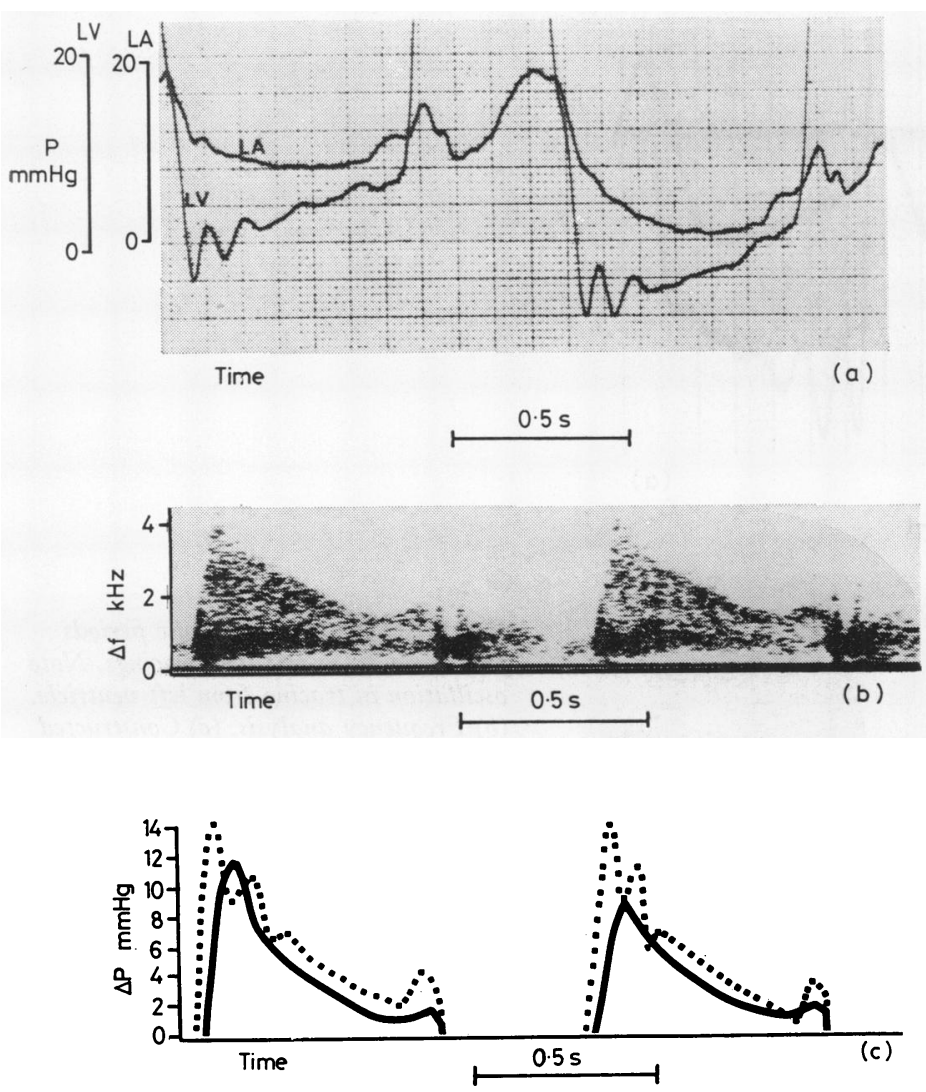

Fig. 4 Consecutive diastolic periods from case 4. (a) Pressure tracings. (b) Frequency analysis. (c) Constructed gradients. Symbols as in Fig. 1. ment found between $\triangle \mathbf{P}_{U}$ and $\triangle \mathbf{P}_{M}$ indicates, however, that the equation predicts the dissipative component of the pressure gradient with reasonable accuracy. This conclusion is supported by the results of previously described in vitro studies of the equation (Holen et al., 1977).

Failure to achieve a probe position where the axis of the incident sound beam coincides with the direction of the vectors with maximum velocity can theoretically lead to a major underestimation of the actual pressure gradient (eq. 1). The confidence that can be placed in the ultrasound technique is undoubtedly enhanced if satisfactory probe positioning can be confirmed by inspection of the frequency analyses, for previous experience with the technique has indicated that the blackened band adjacent to $\Delta f_{\max }$ in the mid-portion of diastole is a sign of this. The band is believed to be the result of the incident sound beam traversing the left ventricle along the mitral jet and thus exposes a large volume of high velocity blood. Failure to achieve correct probe positioning may thus account for the relatively large mid-diastolic discrepancy between $\triangle P_{U}$ and $\triangle P_{M}$ found in case 4. Clearly, the effects of probe position on the appearance of the frequency analyses warrant further study.

\section{Conclusions}

(1) This ultrasound technique appears to determine mean and mid-diastolic mitral valve gradients with an accuracy that is sufficient for diagnostic purposes.

(2) The accuracy of the technique is chiefly limited by the accuracy with which $\Delta f_{\max }$ can be determined from the frequency analyses. (3) The orifice equation (eq. 2) predicts the dissipative component of the pressure gradient with an accuracy that is acceptable for diagnostic purposes. (4) Neglect of the inertial component of the pressure gradient influences the value of the mean gradient very little. (5) A satisfactory probe position ( $\cos \theta=1$ in eq. 1 ) can be attained in the majority of patients with mitral stenosis and can probably be confirmed by inspection of the frequency analyses. 


\section{References}

Diem, K., and Lentner, G. (1962). Documenta Geigy Scientific Tables, 6th edn, p. 547. J. R. Geigy, Basle.

Hertz, H. (1977). Principles of ultrasound in medical diagnosis. In Echocardiography with Doppler Applications and Real Time Imaging, p. 11. Martinus Nijhoff Medical Division, The Hague.

Holen, J., Aaslid, R., Landmark, K., and Simonsen, S. (1976). Determination of pressure gradient in mitral stenosis with a non-invasive ultrasound Doppler technique. Acta Medica Scandinavica, 199, 455-460.

Holen, J., Aaslid, R., Landmark, K., Simonsen, S., and
Østrem, T. (1977). Determination of effective orifice area in mitral stenosis from non-invasive ultrasound Doppler data and mitral flow rate. Acta Medica Scandinavica, 201, 83-88.

Kinsler, L. E., and Frey, A. R. (1962). Fundamentals of Acoustics, 2nd edn, p. 489. Wiley, New York.

Streeter, V. L. (1961). Handbook of Fluid Dynamics, pp. 3-21. McGraw-Hill, New York.

Requests for reprints to Dr Jarle Holen, Department of Radiology, Rikshospitalet, Oslo, Norway. 